\title{
Development Status of the Korean Journal of Child Studies 4 Years After the Suggestions made in 2016
}

\author{
Sun Huh \\ Professor, Department of Parasitology and Institute of Medical Education, Hallym University College of Medicine, \\ Chuncheon, Korea \\ 2016년도 Korean Journal of Child Studies 국제화 제안 이후 \\ 4년 뒤 학술지 발전 양상 \\ 허선 \\ 한림대학교 의과대학 기생충학교실 및 의학교육연구소 교수
}

Objectives: In the first issue of 2016 of the Korean Journal of Child Studies (KJCS), development strategies were proposed. It aimed to examine the changes made in response to each proposal and to suggest steps for further improvement.

Methods: Changes in the characteristics and status of the journal from 2016 to 2020 were described, and new suggestions for further development strategies were proposed. Therefore, this article is a follow-up study of past data.

Results: Among the development strategies proposed in 2016, the following aspects improved: specific aims and scope, official ISO abbreviations, open access declarations, international-level layout, manuscript editing, detailed instructions to authors, and digital standards including Journal Article Tag Suite XML. However, further improvements remain to be made with regard to changing the journal title, obtaining permission to use others' measurement tools, requiring statements of institutional review board (IRB) approval and informed consent, ensuring the long-term tenure of an editor-in-chief, and internationalizing the editorial board membership. The 2015 Web of Science impact factor was calculated as 0.009 , while that of 2019 was 0.04. In contrast, the number of cites per 2 years in Scopus rose from 0.03 in 2015 to 0.07 in 2019.

Conclusion: The above results showed that digital standards have been implemented perfectly. However, articles should specify whether permission was received to use measurement tools and whether IRB approval and informed consent were obtained. The language is recommended to be changed to English to broaden the readership and to increase citation frequency by other international journals.

Keywords: follow-up studies, informed consent, language, publishing, research ethics committees

\section{Introduction}

Background/rationale: In February 2016, I proposed some development strategies for the Korean Journal of Child Studies,

Corresponding Author: Sun Huh, Professor, Department of Parasitology and Institute of Medical Education, Hallym University College of Medicine, 1 Hallymdaehak-gil, Chuncheon, Gangwon-do, Korea

E-mail: shuh@hallym.ac.kr including more professional manuscript editing, internationallevel formatting of the verso page and back matter, improvements of the journal homepage, transformation into an English-language journal, and deposition to PubMed Central (Huh, 2016). Four

(C)The Korean Association of Child Studies

This is an Open Access article distributed under the terms of the Creative Commons Attribution Non-Commercial License (http:// creativecommons.org/licenses/by-nc/4.0) which permits unrestricted noncommercial use, distribution, and reproduction in any medium, provided the original work is properly cited. 
years have passed since I made these suggestions; therefore, it is time to recheck the degree to which the journal has made these improvements to reach the international level.

Objectives: This study aimed to examine the journal's status in terms of its style and format, homepage, and indexing in international databases. The results are compared with the journal's previous status in 2015. These findings may help editors and society board members to plan further strategies to develop the Korean Journal of Child Studies into an international-level journal.

\section{Methods}

Ethics statement: This is a literature-based analysis; therefore, neither institutional review board approval nor informed consent was required.

Study design: This is a follow-up descriptive study analyzing the style and format of the journal, whether it satisfies digital standards for journals, and journal metrics.
Data sources/measurement: The style and format of the April 2020 issue (Volume 41, Number 2) of the Korean Journal of Child Studies was checked based on the International Committee of Medical Journal Editors (ICMJE, http://icmje.org) and Scientific Style and Format 8th edition published by Council of Science Editors (http://www.councilscienceeditors.org/). Journal metrics were calculated from the Web of Science Core Collection (R) on September 7, 2020. The impact factor and total cites were counted. The above results were compared with the issue of December 2015 (Volume 36, Number 6) (Huh, 2016).

Statistical analysis: A descriptive analysis was done. A comparison was made without using statistical techniques because all subjects were included in the data.

\section{Results}

Journal's style and format: Changes of the verso page are presented in Table 1.

\section{Table 1}

Changes of the Verso page of the Korean Journal of Child Studies from 2015 to 2020

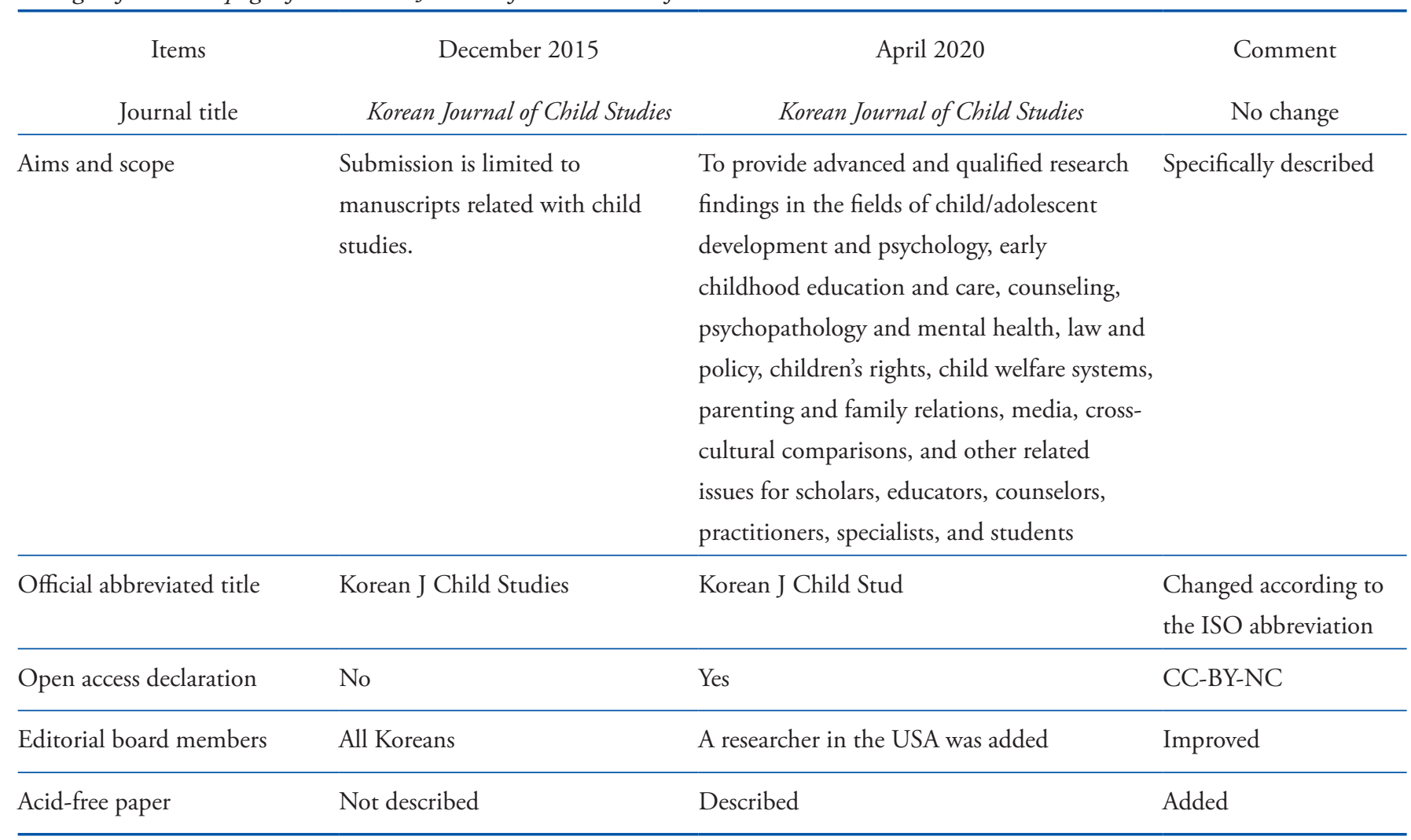


Table 2

Changes of Article-level Content, Style, and Formatting in the Korean Journal of Child Studies from 2015 to 2020

\begin{tabular}{|c|c|c|c|}
\hline Items & December 2015 & April 2020 & Comment \\
\hline Layout & Fair & Excellent & Improved \\
\hline Affiliation & Institution only & $\begin{array}{l}\text { Department, institution, } \\
\text { city, country }\end{array}$ & Fixed \\
\hline Page numbers in one volume & New start in each issue & New start in each issue & $\begin{array}{l}\text { No change; page numbers should be } \\
\text { consecutive in one volume }\end{array}$ \\
\hline Length of main text & No limitation & No limitation & No change \\
\hline $\begin{array}{l}\text { Measurement tool in the Methods } \\
\text { section }\end{array}$ & $\begin{array}{l}\text { Sometimes missing } \\
\text { permission }\end{array}$ & $\begin{array}{l}\text { Sometimes missing } \\
\text { permission }\end{array}$ & No change \\
\hline Manuscript editing & Errors in the text & Perfect & Improved \\
\hline Reference style & APA & APA & No change \\
\hline Publication date of references & No limitation & No limitation & No change \\
\hline
\end{tabular}

Table 3

Changes of Publication type and Ethical Issues in the Korean Journal of Child Studies from 2015 to 2020

\begin{tabular}{llll}
\multicolumn{1}{c}{ Items } & December 2015 & April 2020 & Comment \\
\hline Variety of publication types & Articles only & Research articles only & No change \\
Statements of institutional review board approval or informed consent & Not complete & Not complete \\
Conflict of interest & None & Described completely \\
\end{tabular}

Article-level improvements are presented in Table 2.

The back matter, including instructions to authors and research and publication ethics, was changed as shown in Table 3.

The status of the April 2020 issue in terms of permission for use of measurement tools, IRB approval, and statements of informed consent is presented in Table 4.

The journal homepage and other digital standards were dramatically improved to the top-tier level (Table 5).

Journal metrics: Changes of the impact factor and total cites of the journal from 2015 to 2019 from the Web of Science Core Collection are presented in Figure 1.

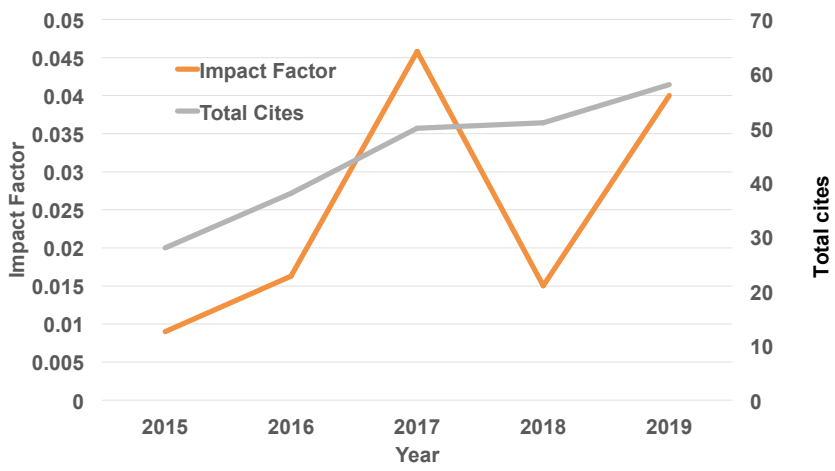

Figure 1. Impact factor and total cites of the Korean Journal of Child Studies in the Web of Science Core Collection from 2015 to 2019 . 


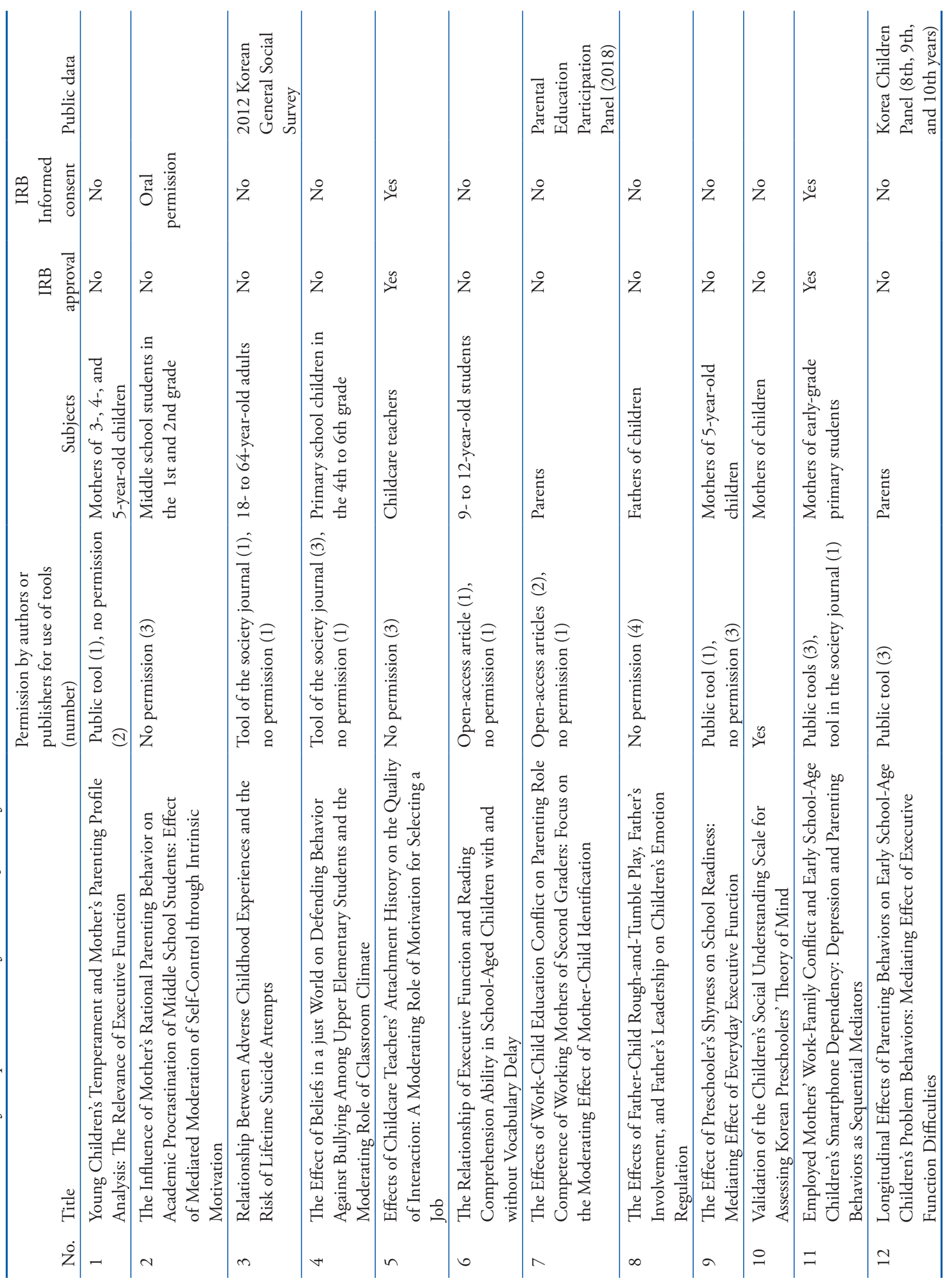


Table 5

Changes of the Journal Homepage and Digital Standards of Journals in the Korean Journal of Child Studies from 2015 to 2020

\begin{tabular}{|c|c|c|c|}
\hline Items & December 2015 & April 2020 & Comment \\
\hline JATS XML & No & Yes & Added \\
\hline DOI & Yes & Yes & Added \\
\hline PubReader & No & Yes & Improved \\
\hline ePub 3.0 & No & Yes & Added \\
\hline CrossMark & No & Yes & Added \\
\hline FundRef & No & Yes & Added \\
\hline Text and data mining & No & Yes & Added \\
\hline ORCID & No & Yes & Added \\
\hline QR code & No & Yes & Added \\
\hline Audio-video file & No & No & No change \\
\hline Manuscript management system & Yes & Yes & Function was improved \\
\hline
\end{tabular}

Note. JATS XML = Journal Article Tag Suite XML; DOI = Digital Object Identifier; ORCID = Open Researchers and Contributors ID; QR code $=$ Quick Response code.

\section{Discussion}

Key results: Among the development strategies proposed in 2016, the following were greatly improved: specific aims and scope, official ISO abbreviations, open access declarations, internationallevel layout, manuscript editing, detailed instructions to authors, and journal digital standards (JATS XML, ePub 3.0, DOI, CrossMark, FundRef, text and data mining, ORCID). However, the suggestions were not followed for the following: change of the journal title; permission to use others' measurement tools; limiting the publication years of the references; requiring a statement of IRB approval (with its number); requiring an informed consent statement; indexing in MEDLINE, Scopus, and SSCI; ensuring the long-term tenure of an editor-in-chief; and internationalizing the editorial board membership. In the Web of Science, the 2015 impact factor was calculated as 0.009 , while that of 2019 was 0.00 . In contrast, the cites per 2 years in Scopus rose from 0.03 in 2015 to 0.07 in 2019 .

Interpretation and suggestion: The above findings reflect the laborious work by editorial board members and the society to improve the journal's style and format. The adoption of digital standards by the journal was impressive. Some suggestions may be difficult to implement, including those regarding the journal title, the language of the text, limiting the publication years of the references, and the editor's term of service.
Of the suggestions that have not yet been implemented, obtaining permission to use others' measurement tools is a copyright issue (Table 4). The Korean Journal of Child Studies is a non-profit scholarly journal, so that no financial gain from the journal is expected. Nonetheless, authors of measurement tools and commercial publishers can raise copyright issues. Korean authors may not insist on copyright because they understand the characteristics of the journal very clearly. However, the situation is different for commercial publishing companies. There has been a previously unreported case in which a commercial publishing company continued to request that a Korean journal editor remove a table containing a measurement tool, even though the journal editor paid the fee for using the tool. Eventually, the table was removed. Although this was a very rare case, this type of issue could occur at any time. Permission to use others' measurement tools should be dealt with using caution. Authors submitting manuscripts to the journal should try to obtain permission from the original authors of measurement tools. However, sometimes, it may be difficult to contact authors, especially if the source is a master's or doctoral thesis. A university cannot provide personal information, including email and telephone numbers, for their graduates. In such cases, the author should inform the editor during the submission process that an attempt was made to contact the author of the measurement tool. The editor of the journal should provide a policy on the use of measurement tools without permission. 
Statements describing IRB approval and informed consent should be seriously considered as a matter of journal policy. Out of 12 articles in the April 2020 issue, two articles analyzing public data could be exempted from the requirement for IRB approval and informed consent. Furthermore, the six surveys administered to adults could also be exempted because there is neither health risk nor privacy infringement to subjects (Korea Ministry of Government Legislation, 2017). In contrast, three articles dealing with child or adolescent subjects provided neither a statement of IRB approval nor a statement of informed consent. In these studies, informed consent from subjects and their parents should have been obtained because they were vulnerable subjects (Table 4).

The present Editor-in-Chief, Joo-Yeon Lee, informed me of the review results by the Scopus Content Selection \& Advisory Board dispatched on August 29, 2020. The Korean Journal of Child Studies was not accepted for Scopus inclusion for the following reasons: few citations by Scopus journals; some of the abstracts are too short and do not provide adequate details; many journals already cover this subject area; and the journal title implies that it is international, but the stated aims and scope do not support this. The last point may not be considered to be a legitimate deficiency because the journal title implies that the journal is local, not international. The abstract format can be fixed immediately through meticulous editing. Citation frequency by Scopus journals may be difficult to improve unless the language of the articles is changed from Korean to English-only. The content of the journal has been excellent. The methods, results, and interpretation of each article were excellent. The quality of the research in this journal has been underestimated due to its language. There is no other option to increase the citation frequency except changing the language to English and depositing the full text of articles to PubMed Central (PMC). PMC is the fulltext biomedical literature database maintained by the United States National Library of Medicine, which accepts English-journals. The scope of the Korean Journal of Child Studies includes psychology; therefore, it is eligible to be added to PMC if it is published in English only. It has been found that if local society journals are included in PMC, the citation frequency of those journals increases dramatically (Jeong \& Huh, 2014). Inclusion in MEDLINE is another way to disseminate the journal to world researchers through PubMed. It is necessary to apply to MEDLINE after meticulously checking the review criteria (Huh, 2017; Huh, 2018).
As for inclusion in the Emerging Sources Citation Index (R) (ESCI), an attempt should be made to apply to the Social Science Citation Index (R) (SSCI). Even though the citation frequency is not high, the journal can be included in ESCI if it satisfies certain criteria.

Comparison with previous studies: It is difficult to find other articles with this kind of meticulous review of a journal's status. Annals of Dermatology published a report reviewing its scientific integrity and ethics statement (Huh, 2020). In that report, it was confirmed that all studies of human subjects or human-derived materials contained statements of IRB approval or informed consent.

Limitation: This study presents the results of a literature search, so some points may not have been checked completely. For example, the original sources of measurement tools may not have been completely checked regarding the applicable copyright policies. If the source is an open-access journal or public documents, there is no need to receive permission; instead, citation of the source title suffices.

Conclusion: Since 2016, the journal's style and format, as well as the digital standards of the journal, have improved to the international level. However, statements regarding whether permission was obtained for the use of measurement tools, IRB approval (with the approval number), and informed consent should be considered as a matter of journal policy. Ongoing efforts should be made to add the journal to MEDLINE, Scopus, and SSCI. If the journal is not listed in an international indexing database in the future, it may be difficult for the editor to continue receiving enough manuscript submissions to sustain the journal. The language should be changed to English only, and the journal editing and publication standards should be maintained in order to add the journal to international indexing databases.

\section{Notes}

This study was presented as a video poster at the 2020 Spring Conference of the Korean Association of Child Studies held in an online-only format on May 20, 2020. 


\section{Conflict of Interest}

No potential conflict of interest relevant to this article was reported.

\section{Supplementary materials}

Supplement 1. Korean summary of the content available from https://doi.org/10.5723/kjcs.2020.41.5.x

\section{References}

\section{In English}

Huh, S. (2017). How to prepare endocrinology and metabolism for reapplication to MEDLINE. Endocrinology and Metabolism, 32(1), 58-61. doi:10.3803/EnM.2017.32.1.58

Huh, S. (2018). Strengthened research ethics, including patient anonymity and informed consent, in MEDLINE and PubMed central journals. Archives of Craniofacial Surgery, 19(4), 241-242. doi:10.7181/acfs.2018.02187

Huh, S. (2020). How annals of dermatology has improved the scientific quality and ethical standards of its articles in the two-year period since October 2018. Annals of Dermatology, 32(5), 353-359. doi:10.5021/ad.2020.32.5.353

Jeong, G. H., \& Huh, S. (2014). Increase in frequency of citation by SCIE journals of non-MEDLINE journals after listing in an open access full-text database. Science Editing, 1(1), 24-26. doi:10.6087/kcse.2014.1.24

\section{In Korean}

Huh, S. (2016). How to promote the Korean Journal of Child Studies to an international journal. Korean Journal of Child Studies, 37(1), 7-16. doi:10.5723/kjcs.2016.37.1.7

\section{Sun Huh http://orcid.org/0000-0002-8559-8640}

Received September 10, 2020

Accepted November 10, 2020 